\title{
Российские и монгольские трудовые мигранты в странах АТP
}

Международный круглый стол "Российские и монгольские мигранты в странах ATP", который был проведён в мае нынешнего года, объединил российских и монгольских исследователей из Дальневосточного фредерального университета (Владивосток, Россия), Института монголоведения, буддологии и тибетологии Сибирского отделения Российской академии наук (Улан-Удэ) и Монгольского государственного университета (Улан-Батор). В онлайн-формате, поскольку сложившаяся эпидемиологическая обстановка не позволила провести мероприятие очно, представители академического и вузовского сообщества обсудили различные аспекты, связанные с исследованием миграционной проблематики. образом:

Основные направления дискуссии были сформулированы следующим

- актуальные проблемы и глобальные тренды, экономические, демографические и социокультурные характеристики современного общества, влияющие на процессы трудовой миграции;

- механизмы формирования и реализации жизненных стратегий и профрессионально-трудовых ориентаций российских и монгольских трудовых мигрантов, выезжающих на заработки в страны Азиатско-Тихоокеанского региона (ATP).

(С Акталов И. Г., Ардальянова А. Ю., Бадараев Д. Д., Винокурова А. В., Костина Е. Ю., мунхбат Оролмаа, Орлова Н. А., Оюунханд Шагдар, Цэрэн Ганбаатар., 2021

АКТАМОВ Иннокентий Галималаевич, канд. пед. наук, доктор фрилософии (Рh.D.), заведующий лабораторией "Центр переводов с восточных языков" Института монголоведения, буддологии и тибетологии Сибирского отделения Российской академии наук (г. Улан-Удэ, Россия) E-mail: aktamov13@gmail.com

АРДАЛЬЯНОВА Анна Юрьевна, канд. социол. наук, доцент департамента социальных наук Школы искусств и гуманитарных наук Дальневосточного федерального университета (2. Bладивосток, Россия). E-mail: ardy2004@mail.ru

БАДАРАЕВ Дамдин Доржиевич, канд. социол. наук, старший научный сотрудник Отдела истории, этнологии и социологии Института монголоведения, буддологии и тибетологии Сибирского отделения Российской академии наук (е. Улан-Удэ, Россия) E-mail: damdin80@mail.ru

ВИНОКУРОВА Анна Викторовна, канд. социол. наук, доцент департамента социальных наук Школы искусств и гуманитарных наук Дальневосточного федерального университета (2. Владивосток, Россия). E-mail: vinokurova77@mail.ru

КОСТИНА Елена Юрьевна, канд. социол. наук, доцент департамента социальных наук Школы искусств и гуманитарных наук Дальневосточного федерального университета (2. Bладивосток, Россия). E-mail: kostina.eyu@dvfu.ru

МУНХБАТ Оролмаа, д-р социол. наук, директор Института социальных исследований Монгольского государственного университета (2. Улан-Батор, Монголия). E-mail: munkhbat@num.edu.mn

ОРЛОВА Надежда Александровна, канд. социол. наук, доцент департамента социальных наук Школы искусств и гуманитарных наук Дальневосточного федерального университета (2. Владивосток). E-mail: orlova.na@dvfu.ru

ОЮУНХАНД Шагдар, Ph.D., доцент кафедры социологии и социальной работы Монгольского государственного университета (2. Улан-Батор, Монголия). E-mail: ondio_d@yahoo.com

ЦЭРЭН Ганбаатар, Ph.D., доцент кафедры менеджмента Монгольского государственного университета (2. Улан-Батор, Монголия). E-mail: tseren@num.edu.mn

При финансовой поддержке РФФИ и МОКНСМ, проект № 20-511-44003 "Российские и монгольские трудовые мигранты в странах АTP". 
Винокурова А.В.: В большинстве дискуссий о миграции отправным пунктом обычно являются цифры. Важно понимать наблюдаемые тенденции и сдвиги в демографических показателях, в том числе и связанных с миграциями. Это будет способствовать лучшему пониманию происходящих в современном обществе трансформаций, прогнозированию дальнейшего социального развития.

Нынешняя ситуация такова, что по последним официальным данным в мире в 2020 г. насчитывалось более 280 млн. международных мигрантов, это приблизительно $3,6 \%$ от общего числа населения нашей планеты. Даже несмотря на ситуацию, связанную с распространением коронавирусной инфекции, пандемией COVID-19, закрытием границ и пр., число мигрантов в мире увеличивается (в 2019 г. общая численность международных мигрантов составляла 272 млн. чел., $3,5 \%$ от общей численности населения мира) ${ }^{1}$.

Ардальянова А. Ю.: Полагаем, что наибольшее число международных мигрантов сосредоточено именно в странах АТР. Так, по данным Международной организации по миграции, в Азии находится 85,6 млн. чел. международных мигрантов; в Северной Америке - 58,7 млн. чел.; в Латинской Америке - 14,8 млн. чел.; в Океании - 9,38 млн. чел. ${ }^{2}$ Разумеется, не вся Азия, Северная и Латинская Америка входят в АТР. Но в целом Азиатско-Тихоокеанский регион включает в себя 58 государств и территорий, расположенных по периметру Тихого океана. В том числе к этому макрорегиону относят самые крупные экономики и рынки мира, например, Китай и США. Кроме того, в ATP включают такие страны, которые не имеют прямого выхода к Тихому океану, в частности, Непал, Монголию, Республику Союз Мьянма, иногда еще и Индию. В составе АТР выделяют несколько основных подсистем: океанскую, азиатскую, североамериканскую и южноамериканскую.

Мунхбат Оролмаа: Коллеги, в соответствии со спецификой нашего исследовательского проекта предлагаю сосредоточить наше внимание именно на азиатской подсистеме АТР, куда входят два основных субрегиона: Восточная Азия (в том числе и Северо-Восточная Азия, включая Россию, в частности, регионы российского Дальнего Востока, и Монголию) и Юго-Восточная Азия.

Оюунханд Шагдар: Говоря об азиатской подсистеме ATP в контексте трудовой миграции, следует отметить, что опять же, несмотря на пандемию COVID-19, закрытие границ и прочие, возникшие в связи с этим барьеры, численность иностранных мигрантов в этом регионе продолжает расти. Так, если в 2019 г. в страны Восточной и Юго-Восточной Азии прибыло около 18,3 млн. чел. международных мигрантов, то в 2020 г. уже - более 19,5 млн. чел. ${ }^{3}$

Винокурова А. В.: Да, цифры говорят сами за себя. Но всё же хотелось бы уточнить, какую долю от всей численности международных мигрантов в АТР занимают монгольские мигранты? И вообще - насколько миграция как стратегия, как сценарий жизни характерна для монголов?

Бадараев Д. Д.: Миграционные процессы всегда играли важную роль в жизни Монголии, обеспечивая освоение территории страны, перераспределяя население и трудовые ресурсы. Интенсивная географическая мобильность является одной из характеристик, имманентных монгольскому миру. В основе этого процесса традиционно лежали природные и экономические мотивы: ко-

1 См. подробнее:

World Migration Report 2020. (publication date: 04 November 2021) [Online] // IOM UN MIGRATION: [website]. URL: https://worldmigrationreport.iom.int/wmr-2020-interactive/ (дата обращения: 08.11.2021).

Доклад о миграции в мире 2020 (дата публикации: 27.11.2020) [Электронный ресурс] // Официальный сайт Международной организации по миграции (https://www.iom.int/). URL: https:// publications.iom.int/system/files/pdf/final-wmr_2020-ru.pdf (дата обращения: 13.10.2021).

2 World Migration Report 2020. (publication date: 04 November 2021) [Online] // IOM UN MIGRATION: [website]. URL: https://worldmigrationreport.iom.int/wmr-2020-interactive/ (дата обращения: 08.11.2021).

3 International Migration 2020 (publication date: 12 July 2021) [Online] // DESA UN: [website]. URL: https://www.un.org/sites/un2.un.org/files/undesa_pd_2020_international_migration_ highlights_updated.pdf (дата обращения: 15.10.2021). 
чевое скотоводство на протяжении веков было не только укладом әкономики, но и образом жизни монголов.

Актамов И. Г.: В настоящее время в современной Монголии формируется иной тип трансграничных миграций, тем не менее ключевым мотивом для временной смены места жительства остаётся әкономический, который тесно связан с уровнем жизни в стране, а также с условиями и возможностями, которые предлагают страны с развитой әкономической инфраструктурой и высокотехнологичными отраслями производства.

Ардальянова А. Ю.: Иннокентий Галималаевич, продолжу. К государствам с развитой экономикой и высокотехнологичными производствами относится и ряд стран АТР. Именно этот макрорегион в последние годы демонстрирует наиболее интенсивный экономический рост и становится всё более привлекательным для трудовых мигрантов.

Орлова Н. А.: Ещё один немаловажный момент: по последним имеющимся оценкам, трудовые мигранты составляют почти две трети от общего контингента международных мигрантов. Однако сопоставление с общей численностью международных мигрантов трудоспособного возраста, а именно в возрасте 15 лет и старше, обнаруживает, что среди них доля трудящихся-мигрантов составляет $70 \%{ }^{4}$. Мы разделяем мнение экспертов, что эти глобальные цифры, скорее всего, занижены. Кроме того, их сложно сравнивать из-за различий в определениях и изменениях в методологии и источниках данных.

Винокурова А. В.: Следующий аспект, на который важно обратить внимание: более двух третей трудовых мигрантов проживают в странах с высоким уровнем дохода. К странам АТР азиатской подсистемы с высоким уровнем доходов относят Японию, Южную Корею и Сингапур. При этом Южная Корея входит в ТОП-10 ведущих стран - отправителей денежных переводов. Доступные данные по Южной Корее показывают, что, допустим, в период 2005-2015 гг. это государство не являлось ведущей страной - отправителем денежных переводов, но уже в 2017 г. Республика Корея заняла по данному параметру 10 строчку рейтинга. Получается, что именно Южную Корею можно рассматривать как одно из наиболее привлекательных для трудовых мигрантов государств АТР.

Мунхбат Оролмаа: Анна Викторовна, вот как раз возвращаясь к вашему вопросу о численности монгольских мигрантов странах АТР, хотелось бы дополнить, что самая большая диаспора монгольских граждан находится именно в Южной Корее. Но оценки касательно их численности весьма противоречивы.

Цэрэн Ганбаатар: Как уже отметили российские коллеги, очень сложно получить объективные данные о количестве иностранных мигрантов, находящихся в той или иной стране. Источники данных разные, методология разная. Вот, например, Организация Объединенных Наций $(\mathrm{OOH})$ приводит данные о 25 тыс. монгольских мигрантов, находящихся в Республике Корея. А, например, Министерство иностранных дел Монголии отмечает, что там проживает 32 тыс. монгольских граждан.

Актамов И. Г.: Также официальные данные не в полной мере учитывают нелегальную миграцию. Хотя Статистическое управление Республики Корея приводит сведения, согласно которым в 2019 г. численность только нелегальных монгольских мигрантов составила 17,5 тыс. чел., увеличившись по сравнению с 2018 г. более чем на 1,5 тыс. чел. ${ }^{\mathbf{5}}$

4 Доклад о миграции в мире 2020 (дата публикации: 27.11.2020) [Электронный ресурс] // Официальный сайт Международной организации по миграции (https://www.iom.int/). URL: https://publications.iom.int/system/files/pdf/final-wmr_2020-ru.pdf (дата обращения: 13.10.2021).

5 См. подробнее:

International Migration Statistics in 2018 (publication date: 18 July 2019) [Online] // Statistics Korea: [website]. URL: http://kostat.go.kr/portal/eng/pressReleases/8/5/index.board?bmode=read\&b Seq=\&aSeq=377860\&pageNo=1\&rowNum=10\&navCount=10\&currPg=\&searchInfo=\&sTarget=title \&sTxt= (дата обращения: 10.10.2021).

International Migration Statistics in 2019 (publication date: 16 July 2020) [Online] // Statistics Korea: [website]. URL: http://kostat.go.kr/portal/eng/pressReleases/8/5/index.board?bmode=read\&b Seq=\&aSeq=384167\&pageNo=1\&rowNum=10\&navCount=10\&currPg=\&searchInfo=\&sTarget=title \&sTxt= (дата обращения: 10.10.2021). 
Винокурова A.В.: Получается, что по самым приблизительным оценкам численность монгольских мигрантов в Республике Корея достигает 40-45 тыс. чел. Коллеги, а какие оценки приводятся касательно численности российских мигрантов в странах АТР, в том числе и в Южной Корее?

Костина Е. Ю.: Наиболее полные и детализированные сведения по международной миграции представлены Департаментом по экономическим и социальным вопросам ООН. В частности, общая численность российских мигрантов в мире в 2019 г. составила около 10,5 млн. чел. ${ }^{6}$ Но для россиян направление АТР, судя по численности находящихся там российских мигрантов, не является самым популярным. В странах Восточной и Юго-Восточной Азии в 2019 г. по официальным оценкам насчитывалось около 20 тыс. мигрантов-россиян, из них чуть более 4,5 тыс. чел. - в Южной Корее.

Винокурова А. В.: Но опять же встаёт вопрос о сопоставлении, полноте статистических сведений, источниках данных о миграции, методиках подсчёта и пр. Например, Статистическое управление Республики Корея на 2019 г. приводит данные о чуть более 12 тыс. нелегальных российских мигрантах, находящихся в этой стране ${ }^{7}$.

Костина Е. Ю.: Вообще, пандемия COVID-19 очень сильно повлияла на изменение миграционных настроений и намерений россиян. С одной стороны, принимая противоэпидемиологические меры, многие страны были вынуждены остановить деятельность в ряде отраслей экономики. Была существенно ограничена работа в сфере услуг и общественного питания, торговли непродовольственными товарами, строительства и транспортных перевозок. Многие иностранные трудовые мигранты, в том числе и российские, потеряли работу. И в самой России произошёл отток трудовых мигрантов, соответственно, в ряде отраслей произошло повышение зарплат, что сделало их привлекательными для россиян, в том числе и имеющих опыт трудовой деятельности за рубежом. К тому же, в такой сложный момент безопаснее находится на родине. Ведь иностранные трудовые мигранты, находящиеся вне своей страны, оказались одними из самых социально незащищённых категорий в период пандемии и локдауна.

Бадараев Д. Д.: Пандемия COVID-19 во многом заставила людей скорректировать свои миграционные планы. Сейчас многие с осторожностью относятся к смене места жительства по причине работы, в том числе и к переезду по трудовым мотивам за рубеж. Также с развитием удалённого формата появилась возможность продвигаться по карьерной лестнице, развиваться в профессии без необходимости переезжать. Развитие форматов удалённой работы открывает новые горизонты для трудоустройства.

Винокурова А. В.: Но всё же такой жизненный сценарий больше характерен для IТ-специалистов и тех, кто занят в сфере цифровых технологий. Несмотря на технологический прогресс, динамично развивающиеся процессы цифровизации, продолжает оставаться высоким спрос именно на "рабочие руки". Например, доля выданных корейской стороной виз категории Е-9 (неквалифицированный труд) для монгольских граждан составляла до $13 \%$, это довольно высокий показатель, который достигается за счёт двусторонних соглашений в данной сорере.

Мунхбат Оролмаа: На формирование миграционных настроений и намерений существенное влияние оказывают показатели социально-экономического развития Монголии, определяющие уровень и качество жизни населения страны, его социальное благополучие в целом. Так, в 2020 г. уровень безработицы в Монголии составил $12,8 \%$. Высока доля лиц, живущих за чертой бедности, она составляет $28,4 \%$ всего населения Монголии, то есть почти

6 См. подробнее: International Migration. 2020 (publication date: 12 July 2021) [Online] // DESA UN: [website]. Available at: https://www.un.org/sites/un2.un.org/files/undesa_pd_2020_ international_migration_highlights_updated.pdf (дата обращения: 23.10.2021).

7 International Migration Statistics in 2019 (publication date: 16 July 2020) [Online] // Statistics Korea: [website]. URL: http://kostat.go.kr/portal/eng/pressReleases/8/5/index.board?bmode=read\&b Seq=\&aSeq=384167\&pageNo=1\&rowNum=10\&navCount=10\&currPg=\&searchInfo=\&sTarget=title \&sTxt= (дата обращения: 10.10.2021). 
треть жителей страны имеет доходы ниже прожиточного минимума. Всё это вынуждает людей искать работу за пределами своего государства.

Орлова Н.А.: В России, именно в Дальневосточном федеральном округе (ДФО), в 2019 г. уровень безработицы составил 6,0\%; численность дальневосточников, имеющих доходы ниже величины прожиточного минимума - $15,1 \%$ (в среднем по всем субъектам, входящим в ДФО). Причинами продолжающейся мигращии из многих дальневосточных регионов выступают: высокая стоимость жилья, плохое состояние инфраструктуры, относительно низкий уровень заработной платы.

Костина Е. Ю.: Человеческий капитал составляет основу для развития экономики и промышленности любого государства, любого его региона. Основными причинами, побуждающими людей сменить место жительства и в значительной степени стимулирующими трудовую миграцию, являются стремление улучшить свое благосостояние, материальное положение семьи, а также невозможность найти какую-либо работу, отсутствие работы по специальности в своём населённом пункте. Россия и Монголия здесь не являются исключениями.

Цәрән Ганбаатар: Большинство монгольских трудовых мигрантов, описывая свой опыт работы в странах ATP, в частности, в Южной Корее, придерживаются единого мнения о мотивах, которые легли в основу их миграционных стратегий. Как правило, это материальный интерес, связанный с возможностью получения более высокого заработка и относительной простотой трудоустройства на хорошо оплачиваемую работу.

Актамов И. Г.: В качестве дополнения обратим внимание на социокультурную составляющую. Особую роль в привлечении монгольских граждан в Республику Корея играет так называемая "корейская волна" - массовая культура, которая очень популярна среди современной молодёжи. Под влиянием культурных паттернов создается максимально положительный образ государства, его жителей, что влияет на выбор страны переезда. Но всё же основными мотивами трудовой миграции, в том числе и для монгольской молодёжи, являются экономические императивы.

Бадараев Д. Д.: Обозначенные аспекты актуальны и для российских мигрантов, в том числе и из Республики Бурятия, которая является одним из основных поставщиков трудовых мигрантов в Республику Корея среди дальневосточных регионов РФ. Рынок труда Бурятии предлагает вакансии, работа, в принципе, есть, однако молодёжь работодателями не особо ценится в силу отсутствия необходимых навыков и опыта, а менее квалифицированный труд связан с низкой заработной платой. Чаще всего, активизация действий, направленных на воплощение миграционных намерений, связана с тем, что молодые люди стремятся улучшить своё материальное положение, включая возможность трудоустройства на должностные позиции с заработной платой выше по сравнению с той, на которую они могут претендовать на родине. И в целом хотят жить в более комфортных условиях, например, иметь более широкие возможности реализовывать свои культурные и досуговые потребности и т. п.

Орлова Н. А.: Современная молодёжь, как российская, так и монгольская, весьма прагматична, ориентирована на высокий доход и высокий уровень потребления.

Ардальянова А. Ю.: Молодым трудовым мигрантам присущ рационализм и ориентация на материальный ресурс, большая часть из которого отправляется на родину, либо используется в последующем для улучшения своего благосостояния именно в своей родной стране.

Мунхбат Оролмаа: Для мигрантов Южная Корея является очень комфортной и безопасной страной. Но всё же есть определённые трудности, и их достаточно много. Это проблемы с оформлением, жильём, знанием языка, взаимодействием с культурной средой, жизненным укладом, в некоторых случаях обман, гендерная дискриминация. Ряд этих проблем, на наш взгляд, являются наиболее значимыми. Прежде всего, это трудности, связанные с оформлением легитимного статуса. Большинство приехали в страну именно по туристической визе, но с дальнейшим намерением остаться работать и, соответственно, находятся в стране нелегально. Получение же официальных 
документов, подтверждающих статус, достаточно сложный и проблематичный процесс.

Оюунханд Шагдар: Немаловажной проблемой для всех иностранных трудовых мигрантов в странах АТР, в том числе и в Республике Корея, становится язык. Многие отмечают тот факт, что даже со знанием английского языка работать очень сложно. Знание же корейского языка облегчает не только бытовое общение, но и уменьшает риск быть обманутым недобросовестным работодателем.

Ардальянова А. Ю.: Попадая в трудные жизненные ситуации, связанные со здоровьем, обманом, потерей документов, монгольские трудовые мигранты чаще всего обращаются к близким людям (друзьям, товарищам и "коллегам" по работе), если складываются хорошие отношения с работодателем, то нередко обращаются к нему, но при этом достаточно распространена практика "вычитания" из заработной платы работников тех расходов, которые понесёт работодатель (например, за восстановление документов или оказание медицинских услуг).

В целом же большинство как российских, так и монгольских трудовых мигрантов "исповедуют" краткосрочные, возвратные миграционные стратегии. Планируют в перспективе вернуться на родину, объясняя свой статус в Южной Корее как временный. Мигранты не чувствуют особого расположения со стороны принимающего сообщества.

Винокурова А.В.: Подводя итоги нашего круглого стола, можно отметить, что главным мотивом трудовой миграции как для россиян, так и для граждан Монголии является улучшение своего материального благополучия, накопление стартового капитала для дальнейшего собственного личностного развития на родине. Основным әлементом, который препятствует закреплению трудовых мигрантов в странах АТР, являются административные и культурные барьеры, выстраиваемые государствами вполне осознанно. Получение легального статуса является сложной процедурой, а поступление на достойную работу зависит не только и не столько от "ценности" мигранта на рынке труда, а от того, насколько он включён в уклад жизни, культуру и историю принимающей страны. Именно потому стратегия пребывания российских и монгольских трудовых мигрантов в странах Азиатско-Тихоокеанского региона по большей части является краткосрочной, временной и в основном реализуется молодыми людьми. 
Актамов И. Г., Ардальянова А. Ю., Бадараев Д. Д., Винокурова А. В., Костина Е. Ю., Мунхбат Оролмаа, Орлова Н. А., Оюунханд Шагдар, Цэрэн Ганбаатар. Российские и монгольские трудовые мигранты в странах АTP.

Ключевые слова: миграционные процессы, российские и монгольские трудовые мигранты, профбессионально-трудовые ориентации, жизненные стратегии, уровень и качество жизни, социально-эконолическое благополучие, Азиатско-Тихоокеанский регион

Aktamov I. G., Ardalyanova A. Yu., Badaraev D. D., Vinokurova A. V., Kostina E. Yu., Munkhbat Orolmaa, Orlova N. A., Oyuunkhand Shagdar, Tsehrehn Ganbaatar. Russian and Mongolian Migrant Workers in the Asia-Pacific Region.

Key words: migration processes, Russian and Mongolian migrant workers, professional and employment orientations, life strategies, level and quality of life, socioeconomic well-being, Far East, Asia-Pacific region

Для цитирования: Актамов И. Г., Ардальянова А. Ю., Бадараев Д. Д., Винокурова А. В., Костина Е. Ю., Мунхбат Оролмаа, Орлова Н. А., Оюунханд Шагдар, Цэрэн Ганбаатар. Российские и монгольские трудовые мигранты в странах АТР // Ойкумена. Регионоведческие исследования. 2021. № 4. С. 56-62. DOI: 10.24866/1998-6785/2021-4/56-62

For citation: Aktamov I. G., Ardalyanova A. Yu., Badaraev D. D., Vinokurova A. V., Kostina E. Yu., Munkhbat Orolmaa, Orlova N. A., Oyuunkhand Shagdar, Tsehrehn Ganbaatar. Russian and Mongolian Migrant Workers in the Asia-Pacific Region // Ojkumena. Regional researches. 2021. № 4. P. 56-62. DOI: 10.24866/1998-6785/2021-4/56-62 